\title{
PatternMagix Construction Kit Software
}

\author{
Edith Ackermann \\ Carol Strohecker \\ Appears in Extended Abstracts, CHI 2001 (Design Expo), ACM Press \\ Originally appeared as MERL Technical Report 2000-33
}

\begin{abstract}
PatternMagix is a game-like software construction kit. Its constructive-dialogic style of interaction supports learning through playful exploration. In the course of creating colorful tiles and patterns, learners explore geometric symmetry. Their moves alternate with automatic moves of the computational device so that the interactions resemble turntaking in a dialog.
\end{abstract}




\section{PatternMagix Construction Kit Software}

\author{
Edith Ackermann \\ Design Inquiry Group, Dept. of Architecture \\ Massachusetts Institute of Technology \\ Cambridge, MA 02139 USA \\ $+16178648446$ \\ edith@media.mit.edu
}

\author{
Carol Strohecker \\ MERL - Mitsubishi Electric Research Laboratories \\ 201 Broadway \\ Cambridge, MA 02139 USA \\ $+16176217517$ \\ stro@merl.com
}

\begin{abstract}
PatternMagix is a game-like software construction kit. Its constructive-dialogic style of interaction supports learning through playful exploration. In the course of creating colorful tiles and patterns, learners explore geometric operations, like rotation and symmetry. Their moves alternate with automatic moves of the computational device so that the interactions resemble turn-taking in a dialog.
\end{abstract}

\section{Keywords}

constructive-dialogic interaction, negotiational control, learning, geometric symmetry, patterns

\section{INTRODUCTION}

People exercise varying degrees of control in interacting with computational systems. The desktop model is one of unilateral control; for all its benefits in terms of preference or efficiency, the user's psychological mindset is arguably one of domination. Collaborative systems can provide opportunities for experimenting with different psychological starting points. Work in the Design Inquiry Group at MIT demonstrates ways of visualizing activity that occurs in a system even when the user is not interacting [10]. The activity may occur as a result of system processes or other people's interventions, as in a workgroup situation. In either case the continuous spatial shifts and information reorganizing reflect a view of the system as dynamic and the user as a participant in ongoing transactions.

Here we describe a software design that accommodates and encourages - a range of psychological positions as the user interacts. We refer to this person as the "player," because the system has game-like qualities. However, it is neither competitive in nature nor tiered in structure. Rather, PatternMagix is a tool for learning [15]. Users play in a world of colorful tiles and geometric operations, from which they forge mosaic-like patterns. Interactions are modeled as a conversation between the player and the system. The dialogic turn-taking manifests as spatial changes in the display of constructions and system states.
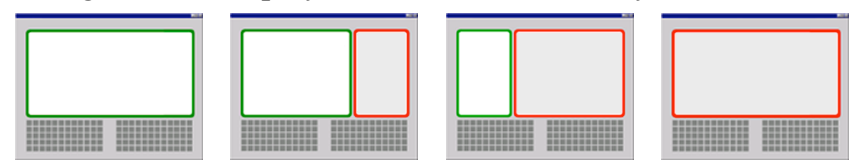

\section{PROBLEM SETTING AND DESIGN PRINCIPLES}

We work in the constructionist tradition, which holds that learning happens especially well when the learner is engaged in creating personally meaningful things that can be shared with others $[6,9]$. In designing computational media as partners for learning, we consider which aspects of the constructive process are best performed by the person and which can best be performed by the system. In addition to leveraging computational advantages such as external memory and dynamism, we focus on shared exploration, leaving the creative part to the person (or persons).

Many computational tools for learning are based on the assumption that control is unilateral: either the learner controls the machine, or the machine controls the learner. The Logo programming language and many dynamic modeling tools are examples of the former, constituting an important view of learner-centeredness [2, 3, 9, 11]. Tutoring systems are an example of the latter: the old-style automated tutors purported to be interactive by providing students with opportunities to make choices, but the program of instruction was generally fixed, thereby restricting possibilities for learning in any deep sense. More recently, "intelligent tutors" employ parameter settings and adaptive, behind-the-scenes filters that characterize users' interactions, thereby developing "user models" that help to create somewhat more personalized experiences $[14,18]$.

We find ourselves at an interesting middle ground with respect to these approaches. Acknowledging the great diversity in human learning styles [17], and asserting that "style" pertains to issues of control, we address potential benefits of situations in which learners can share control. We maintain constructivist principles but further address who is doing the building and how the building happens.

\section{CONSTRUCTIVE-DIALOGIC INTERACTION}

In their two volumes on constructionism, Papert et al. substantiate how the insights of Piaget, Dewey, Bruner, and Vygotsky can be combined with today's technological capabilities to extend the scope of Piagetian constructivism $[6,7]$. A key addition is the notion of learning as design. Like Schön, we consider design as a "conversation" with 
artifacts [4, 12, 13]. Our formulation of constructivedialogic interaction reflects the premises that ideas can be made accessible through building, that building can happen through negotiational processes, and that the resulting objects can be sharable.

Cognitive theorists, including constructionists, address the importance of negotiation in establishing a distinction between two kinds of builders: planners and bricoleurs $[8$, 16, 17]. Planners know in advance what steps they will take in order to get something done. If they are chefs, they write a recipe and then follow it. If they are writers, they develop an outline and stick to it. In general, planners prefer to use materials and ingredients designated for a given task rather than improvising. Bricoleurs, on the other hand, typically do not know ahead of time how they will go about doing something, and may not know what they will use in order to get the job done. They collect objects that seem interesting or potentially useful, and bring them into a situation as the need arises. Often, new goals emerge in the course of work: bricoleurs use unexpected side-effects as springboards for how to proceed.

Constructive-dialogic interaction allows for the approaches of both planners and bricoleurs, but provides affordances that may be particularly appealing to the latter. It acknowledges the situated approach characteristic of bricoleurs as a way of developing useful, elegant results.

Adding conversational turn-taking to the building of personally meaningful products goes beyond the question of how the building happens, to who is doing the building $[1,19]$. Bakhtin reminds us that a thinker, designer, or learner is never alone, but carries within a collection of voices reflecting influences of others, as well as the thinker's own ideas. The "voices" with whom a thinker interacts may be of people present or absent at a given time, and these voices may be fictional rather than real. The attempt to create coherence among many voices is, for Bakhtin, at the core of human intelligence and forms the basis of both internal and external "worldmaking" and meaning-making [5]. Hence interactions are like conversations, and they may be with oneself, another person (or persons), or a person's legacy as embodied in a tool, a toy, or a computational kit.

\section{PATTERNMAGIX INTERACTION DESIGN}

PatternMagix players select elements to build colorful tiles, and experiment with geometric transformations by rotating an element or reflecting it around the $\mathrm{x}$ - or $\mathrm{y}$-axis. When a construction is complete, the player clicks the area at right.
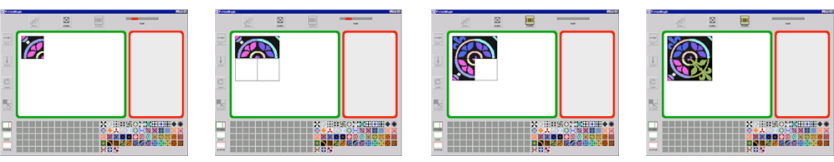

The Build and Activate areas change size, and PatternMagix interprets the contents of the grid as a tile, which it shrinks and replicates to create a pattern. The system metaphorically suggests possibilities for new tiles as a frame floats around the pattern. The player can capture a delineated portion and use it in further constructions.
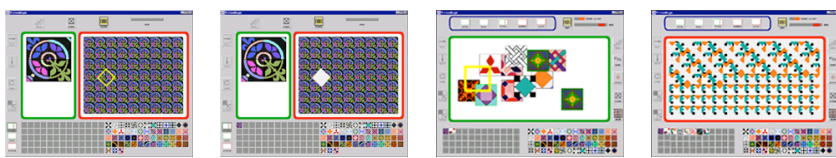

PatternMagix also has two modes in which the Build area expands to its maximum width and the player's creations result solely from direct manipulation. Here the "conversational" style is more monologic and the player has maximal control. In a future Draw mode, the player creates freehand decorations for tiles. In Quilt mode, tiles dragged from the library become "patches" in a freeform "quilt." The player can use the frame to bound and save new areas across patches. In two automatic modes, the Activate area expands to its maximum width, and the system generates variations of user-crafted patterns. The player relinquishes control temporarily but can contemplate the evolving transformations and use them as inspiration for further constructions. In Shuffle mode, the system applies series of geometric transformations. In a future Kaleid mode, the system varies basic tile shapes: squares can become triangles, hexagons, or other intermingling forms.

\section{FURTHER INQUIRY}

We are conducting trials of the current prototype at Boston's Museum of Science. In addition to plans for completing the Draw and Kaleid modes, we are considering tangible input devices. We also have designs for other kits based on constructive-dialogic interaction, which emphasize notions of emergence: properties of constructions play out as dynamic behaviors, illustrating complexities of multivariate systems.

\section{ACKNOWLEDGMENTS}

Edith Ackermann, Carol Strohecker, and Aseem Agarwala designed and developed PatternMagix. Doug Smith and Sue Sunbury are facilitating the museum trials. PatternMagix is among a genre of constructivist software kits being developed by collaborators at MERL [15].

\section{REFERENCES}

1. Bakhtin, M. 1981. The Dialogic Imagination. M. Holquist, ed., C. Emerson and M. Holquist, trans. Austin: U. Texas Press.

2. DiSessa, A. 1993. Towards an epistemology of physics. Cognition and Instruction 10:2 \& 3, 105-225.

3. Edwards, L. 1994. Microworlds as representations. Santa Cruz: Crown College, U. California.

4. Fischer, G., and K. Nakakoji. 1992. Beyond the macho approach of artificial intelligence. Knowledge-Based Systems 5:1, 15-30.

5. Goodman, N. 1978. Ways of Worldmaking. Indianapolis: Hackett.

6. Harel, I., and S. Papert, eds. 1991. Constructionism. Norwood, NJ: Ablex.

7. Kafai , Y., and M. Resnick, eds. 1996. Constructionism in Practice. Mahwah, NJ: Lawrence Erlbaum.

8. Levi-Strauss, C. 1962. The Savage Mind. U. Chicago Press.

9. Papert, S. 1980. Mindstorms. New York: Basic Books.

10. Porter, W., E. Ackermann, P. Keel, et al. 2000.

11. Resnick, M. 1994. Turtles, Termites, and Traffic Jams. MIT Press. 
12. Schön, D. A. 1983. The Reflective Practitioner. NY: Basic Books.

13. Schön, D. A. 1992. Designing as reflective conversation with the materials of a design situation. Knowledge-Based Systems 5:1, 3-13.

14. Sleeman, D., and J. S. Brown, eds. 1981. Intelligent Tutoring Systems. London: Academic Press.

15. Strohecker, C., and A. H. Slaughter. 2000. Kits for learning and a kit for kitmaking. Extended Abstracts, CHI'2000 (The Hague, Netherlands, 2000), ACM Press.
16. Suchman, L. 1987. Plans and Situated Actions. Cambridge U. Press.

17. Turkle, S., and S. Papert. 1990. Epistemological pluralism: Styles and voices within the computer culture. Signs 16:1.

18. Wenger, E. 1988. Arificial Intelligence and Tutoring Systems. Los Altos, CA: Morgan Kaufmann.

19. Wertsch, J. 1991. Voices of the Mind. Harvard U. Press. 